\title{
Development of Detailed Micro-Land Form Database and Its Application to Site Amplification Characteristics in Kanagawa Prefecture, Japan
}

\author{
Tsutomu Ochiai ${ }^{1}$, Takahisa Enomoto ${ }^{2}$ \\ ${ }^{1}$ Kozo Keikaku Engineering Inc., Tokyo, Japan \\ ${ }^{2}$ Kanagawa University, Kanagawa, Japan \\ Email: Tsutomu-ochiai@kke.co.jp
}

How to cite this paper: Ochiai, T. and Enomoto, T. (2019) Development of Detailed Micro-Land Form Database and Its Application to Site Amplification Characteristics in Kanagawa Prefecture, Japan. Journal of Geographic Information System, 11, 66-81.

https://doi.org/10.4236/jgis.2019.111006

Received: November 22, 2018

Accepted: February 19, 2019

Published: February 22, 2019

Copyright $\odot 2019$ by author(s) and Scientific Research Publishing Inc. This work is licensed under the Creative Commons Attribution International License (CC BY 4.0).

http://creativecommons.org/licenses/by/4.0/

\section{(c) (i) Open Access}

\begin{abstract}
Structural characteristic of surface soil ground has great effect on the ground motion amplitude when earthquake happens. Recent studies in Japan on seismic zonings use a database that covers entire Japan with $1 \mathrm{~km}$ mesh size, which is useful for prefecture scale researches. However, it is hard, even with $500 \mathrm{~m}$ or $250 \mathrm{~m}$ mesh sizes to consider a city, a county or award as scale studies. Kanagawa Prefecture is highly urbanized and vulnerable to seismic disaster. The prefecture suffered a wide spread damage during the 1923 Kanto earthquake. In this paper, we deploy a very fine mesh $50 \times 50 \mathrm{~m}$ mesh to develop a general seismic intensity map useful for micro scale disaster management for local governments and educational information for earthquake preparedness promotion. In this paper, first we prepared two detailed databases for $50 \times 50 \mathrm{~m}$ mesh size over entire Kanagawa Prefecture. One was for geologic formations and the other the geomorphologic condition. Then these databases were used for preparation of high-resolution digital soil classification maps for 15 categories of micro landforms of prefecture. The later database was used for mapping the site amplification factors for $50 \times 50 \mathrm{~m}$ mesh by applying the empirical relations for AVS30. We could create a GIS platform with sufficient accuracy to consider potential risk analysis.
\end{abstract}

\section{Keywords}

Micro-Landform, GIS, Site Response, Site Amplification Factor, Geologic Database, Geomorphologic Database 


\section{Introduction}

Structural characteristic of surface soil ground has a great effect on the ground motion amplitude when earthquake happens. It is necessary to master the characteristic of the soil ground on objective sites or areas to evaluate damage risk degree and investigate damage prediction of seismic disaster. Also when using seismic design, it is necessary to use the master the characteristic of the soil ground (Eurocode No. 8 [1]; NEHRP [2]). In Japan, based on several studies (Fujiwara et al. [3]; Midorikawa et al. [4]), NIED is recommending database of topography across the country (NIED [5]). In Europe, many hazard maps using ground characteristics like Navarro et al. [6], Benito et al. [7], Gaspar-Escribano et al. [8], Rota et al. [9], and Navarro et al. [10] are maintained, and it is the same in the United States (Pertersen et al. [11]).

Now a few methods have been developed. Two approaches based on the ground survey, i.e. collection of borehole data and classification of geomorphological and geological conditions are possible to be applied, by which the soil physical attributions of a recording site such as the average share wave velocity (AVS) are calculated and then the amplification characteristic is estimated. However, the approach of borehole data collection meets its limitation in damage assessment system of large areas. For the topographical class has a close relationship with seismic damage, a few of databases of surface soil ground are being constructed in Japan, and are applied to evaluate the strong ground motion distribution simply.

Several recent studies in Japan on seismic zonation employ the geomorphological and geological information provided by Digital National Land Information (DNLI), which is a database, covers entire Japan with a $1 \mathrm{~km}$ size mesh. Now the National Research Institute for Earth Science and Disaster Prevention (NIED) is developing the digital map of surface ground with $500 \mathrm{~m}$ and $250 \mathrm{~m}$ mesh size, to show the ground characteristics. The database with $1 \mathrm{~km}$ mesh size can get the topographical information of a prefecture. However, considering detailed information such as cities and counties, mesh sizes of $500 \mathrm{~m}$ or $250 \mathrm{~m}$ are not enough. The difference between $50 \mathrm{~m}$ mesh and $250 \mathrm{~m}$ mesh is shown in Figure 1.

The $50 \mathrm{~m}$ mesh can reproduce detailed topography. But, $250 \mathrm{~m}$ mesh cannot reproduce the detailed topography.

The Cabinet Office has summarized how to prepare seismic disaster prevention maps (The Cabinet Office [12]). In this study, using this method, detailed digital topographical class of Kanagawa prefecture is manufactured [13]. Kanagawa prefecture is located near the center of Japan. In addition, the 4 plate ( $\mathrm{Pa}$ cific plate, Philippine sea plate, Eurasian plate, North American plate) boundaries overlap each other, and earthquake activity is very active globally as well (Figure 2) [14]. According to Moroi et al. [15], in Kanagawa Prefecture, damage to wooden houses was greatly impaired by the 1923 Kanto earthquake (Figure 3). 


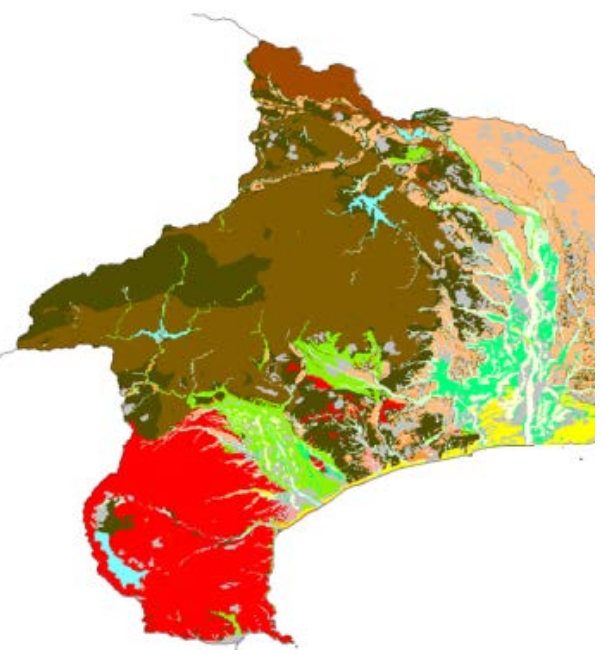

(a)

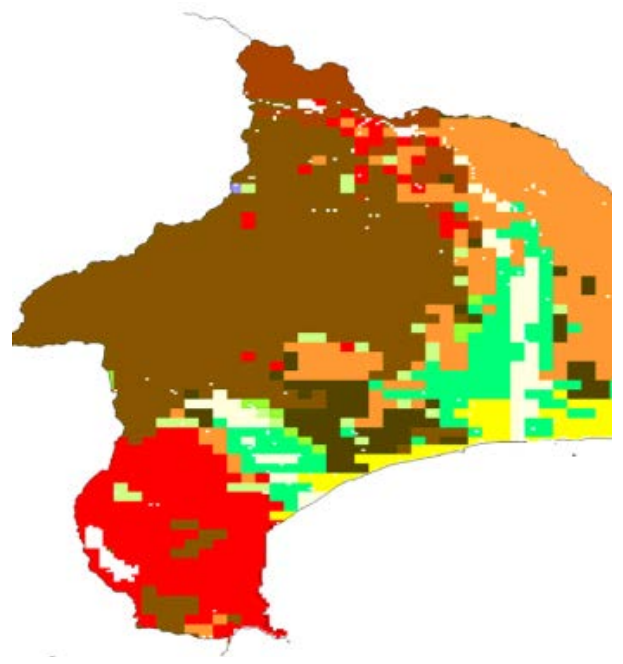

(b)

Figure 1. Difference between $50 \mathrm{~m}$ mesh and $250 \mathrm{~m}$ mesh (Topography of Western Kanagawa Prefecture). (a) $50 \mathrm{~m}$ mesh; (b) $250 \mathrm{~m}$ mesh.

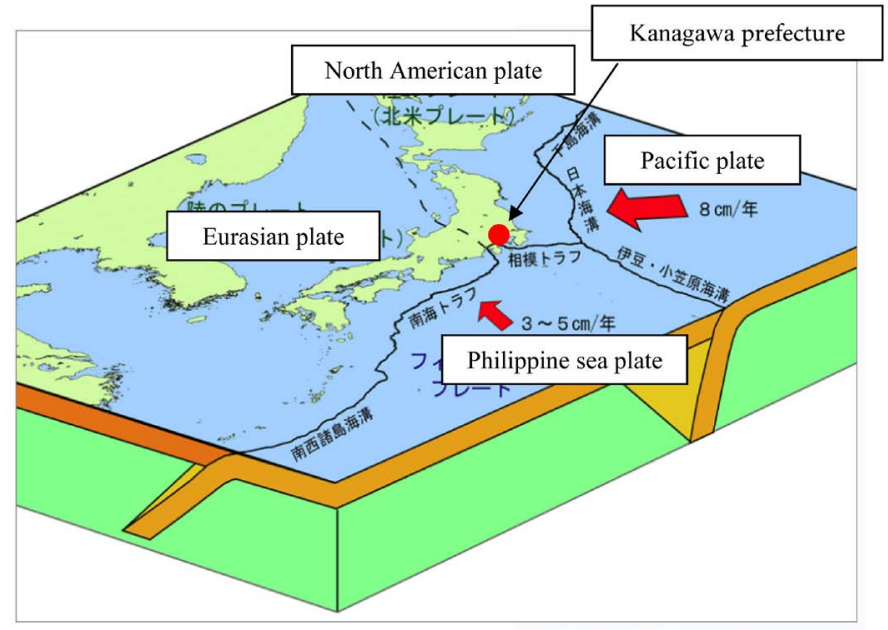

Figure 2. Kanagawa prefecture and plate boundary (Japan Metrological Agency) [14]. 


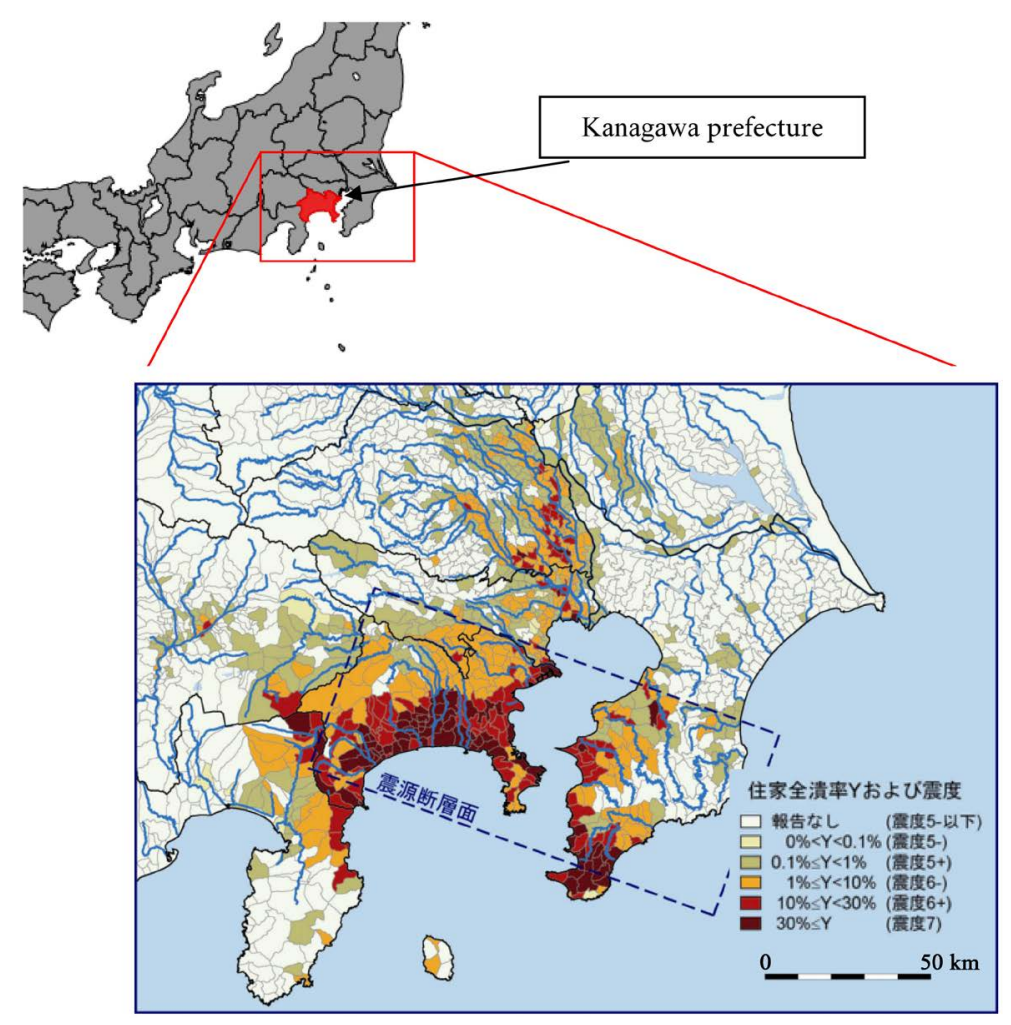

Figure 3. Wooden House Collapase ratio.

Kanagawa prefecture is advancing urbanization, the industry has grown greatly and the population of the Kanto region is concentrated. Also, as there are many sightseeing spots such as Kamakura and Hakone, many tourists visit, including foreigners.

It has great value to precisely classify the topographical to a degree of each ward, and then to develop a general seismic intensity map for the residents having proper image of the potential hazard.

In this paper, the manufacture method of the digital soil classification map is introduced firstly using geographic information systems (GIS). Two types, i.e. geomorphological and geological map, of Kanagawa prefecture with 1/50000 scale published by Geographical Survey Institute (GSI) are input into ArcGIS Desktop by properly defined coordination system of land survey. New maps having geomorphological or geological characteristic are developed by using the Desktop, and geomorphological or geological attributions are input respectively, and 50m meshed digital topographical maps and databases, which are fit for the administration of GIS, are built. According to the processing proposal of micro-landform classification from Central Disaster Management Council, 15 categories of micro-landform classification is formed based on the $50 \mathrm{~m}$ meshed geomorphological or geological data. At last, with the experience formulae proposed by Midorikawa (Midorikawa et al.) [16] and Fujimoto (Fujimoto et al.) [17], the relationship of micro-landform and AVS30 is defined and the amplification ratios of surface ground is estimated. It is possible to form the earthquake 
intensity map of the whole prefecture, and this part of research job is being continued.

\section{Digitalizing of Soil Classification Map by GIS}

\subsection{Desktop of ArcGIS}

ArcGIS Desktop is used as tools to digitize the maps. It is a software provided by ESRI. ArcGIS has strong functions and is efficient to deal with getting, saving, updating, manufacturing, showing and administrating of geological information. Many functions have been used for the manufacture of the map, such as the space index, space data complication, space topology, and coordination transformation, etc., by which the process is carried out efficiently.

\subsection{Base Map Used for the Digitalization}

Geographical Survey Institute (GSI) has published two types, i.e. geomorphological and geological map, of Kanagawa prefecture having a scale of 1/50,000. The maps have TIFF format and are used as base maps in the study. 7 parts of geomorphological or geological map according to the whole prefecture are divided. Figure shows an example of geomorphological map bounded by broad lines. In addition, a comparison is given between the separated geomorphological map and the norm zone mesh according to a scale of $1 / 50,000$, which is bounded by thin lines.

To input the TIFF file into the ArcGIS, there needs a Land survey control system, which gives a method to survey and identify land parcels in earth. There are several land survey control systems have been built, such as Land survey result 2000, World geodetic system 1984, Japan land survey system, and Japan geodetic 2000 etc. Different positions and shape of the map will be exhibited depending on the selected land survey control system. As shown in Figure, big error of maximum value approaching to $500 \mathrm{~m}$ has appeared when world geodetic system 1984 and Japan land survey system use for control system. Therefore, it is important to select the land control system to be the same one and fit other comparable survey land system. However, the ArcGIS has the function of coordination system transformation, which will bring great convenient. In this study, the old land survey system of Japan is used by the base geomorphological map and geological map. The system needs to be transformed to the Japanese land survey system 2000 after the digital map is formed. In addition, many object coordination systems have been used in ArcGIS software. In this study, the Universal Transverse Mercator grid system that is generally used is adopted for the coordination system.

\subsection{Manufacture Process of the Digital Map}

Taking the geomorphological map to be an example, the manufacture process of the digital map is introduced. The flow is shown in Figure 4. 


\section{Geomorphological and Geological map of Kanagawa prefecture}

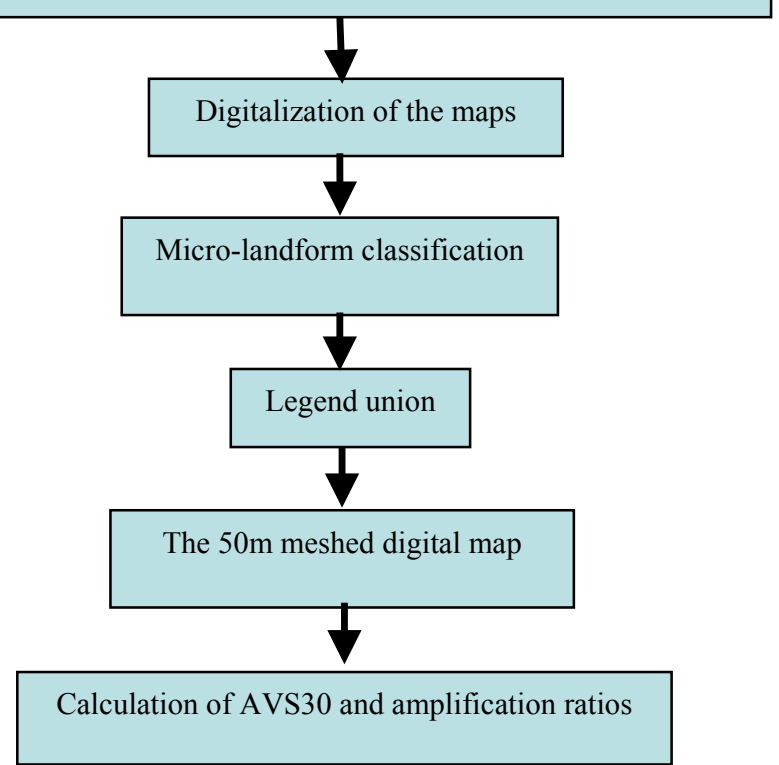

Figure 4. Diagram for the calculation of amplification ratios.

The first step is to input the base map to the ArcGIS, the margin of the 7 parts of geomorphological map is cut, and arrange them to be one map shown as Figure 5. As a base map of TIFF format, there are points having their longitude and latitude, which are found and defined as control points shown in Figure 6. Then a new point shape file is formed in the ArcGIS, which shows the control points too. Open the base map in the ArcGIS; it will be found the base map does not have its identified position. Link the control points of the base map to the according points that have same coordinates in point shape file of ArcGIS, it will get its right position shown in Figure 6.

The next step is to digitize the map. A new line shape file is built in the ArcGIS over the base map, and input its coordination system. To zoom the base map to be large enough and set the line shape file to be transparent, lines are drawn by tracing the boundary of polygons in base map, which have their geomorphological attributions. It is necessary to notice the lines should be closed for every polygon, which means the lines must cross at the terminal points. However, multiple cross should be avoid, otherwise micro polygons will be produced. Figure 7 gives the error result examples if the lines are not traced properly. After the line shape file is finished, a function of ArcGIS can be used to change the line shape file to be polygon shape file. However, the polygon shape file has not its attributions yet. Position the polygon shape file over the base map, and set the polygon shape file to be transparent. By identifying the color and name of the category polygon in base map, and comparing them with the legend, the identification numbers that define the polygon attribution can be input the table attributions in the ArcGIS. Now seven parts of digital map have been manufactured. 


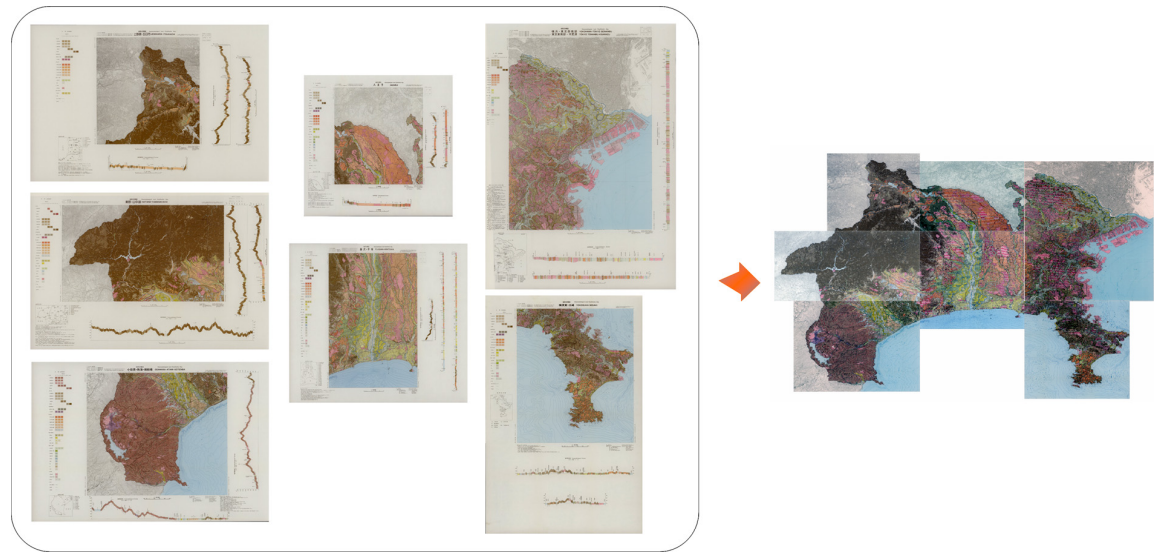

Figure 5. Seven parts of geomorphological map with TIFF format and their unification.

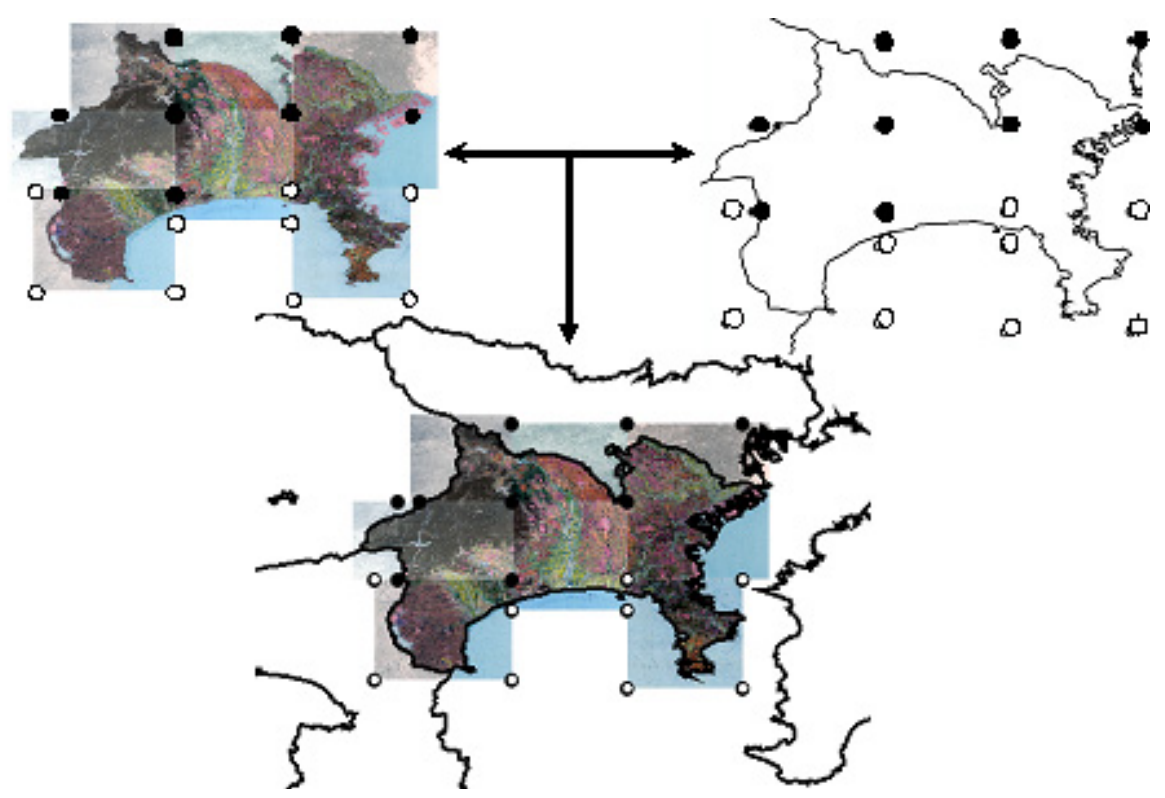

Figure 6. Processing to input the base map into the ArcGIS with its coordination system.

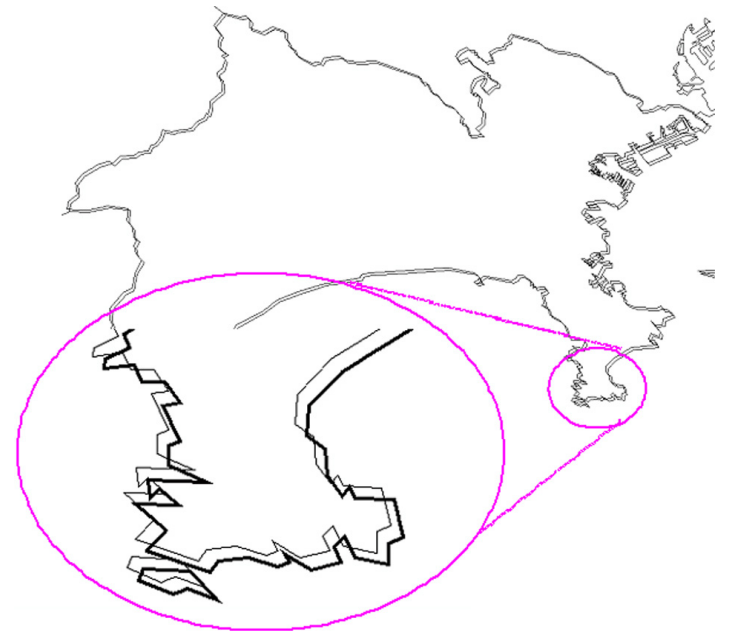

Figure 7. Position errors exhibited by different land survey system (thin line: world land survey system; broad line: old land survey system of Japan). 
The same process of digitalization is carried out for the geological map. Figure 8 and Figure 9 give the digital results of geomorphological map and geological map. It will be shown that the geomorphological map has identical color series for the seven parts of the map because each part of the map uses the same legend and the color series are rather different for the seven parts of geological map. Table 1 gives the identification numbers of seven parts of geological map. It can be seen different identification numbers of seven parts have shown the same attribution. By the unification of the numbers, a whole identification number series are built. However, the geological classification is a rather complex system. The legend of the geological map includes not only the information of physical material such as sand etc., and the deposit environment to form the stratum such as fan, back marsh, lacustrine, etc., but also the information of geological function such as formation etc. In this study, after comparing the geological periods, the detail items of geological categories in the base map shown in Table 2 are compared properly and formulated. Furthermore, if some parts are not recorded in the geological map, the judgment is made by the investigation of other reference and in site survey. Table 3 gives the period classification, which has the same width as the general geological map. After the unification, it can be shown by Figure 10, that the color series of 7 parts of geological map are identical, and the detail information of the period attributions are exhibited.

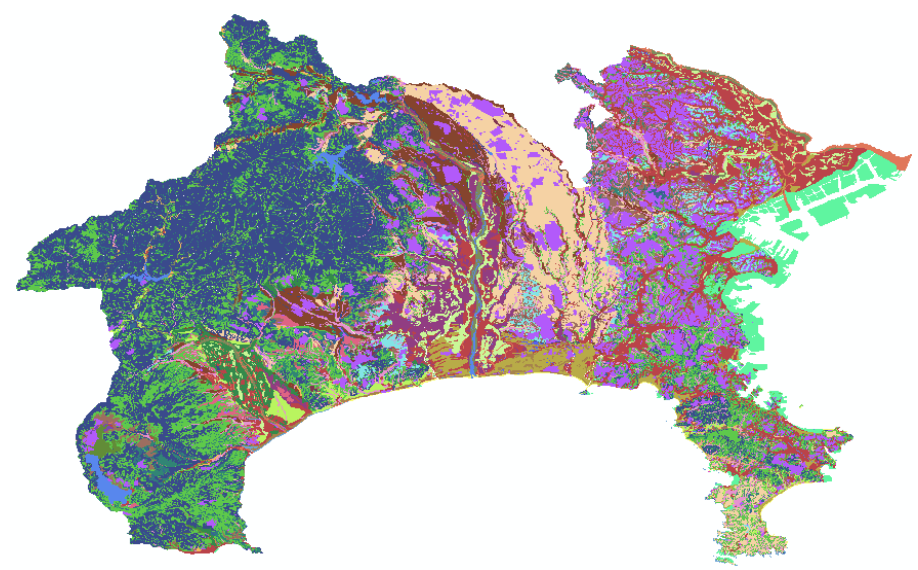

Figure 8. Result of digital geomorphological map.

Table 1. Comparison and unification of the geological map of surface ground.

\begin{tabular}{|c|c|c|c|c|c|c|c|c|c|c|c|}
\hline ID & Periods & Stratigraphy & Layer phase & Code & \multicolumn{7}{|c|}{ ID number of 7 geological maps } \\
\hline 1 & Docont & Artificial materials & Reclaimed fill & Fs & 1 & 1 & 1 & 1 & 1 & 1 & 1 \\
\hline 2 & Recentit & Artificial materials & Fill & $\mathrm{F}$ & & & & & & & 2 \\
\hline 3 & & Talus sediment material & Gravel, sand, mud & $\mathrm{D}$ & & & & 2 & & & 3 \\
\hline 4 & Holocene & Current river bed & Gravel, sand, mud & & & 2 & 2 & 3 & 2 & & \\
\hline 5 & 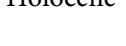 & Abandoned channel & Sand \& others & $\mathrm{Aa}$ & & & & & & 2 & \\
\hline 6 & & Marine fluvial deposit & Sandy deposits & $\mathrm{Am}$ & 2 & 3 & & 4 & 3 & 3 & 4 \\
\hline$\ldots$ & $\ldots$ & $\ldots$ & $\ldots$ & $\cdots$ & $\ldots$ & $\ldots$ & $\ldots$ & $\ldots$ & $\cdots$ & $\ldots$ & ... \\
\hline
\end{tabular}


Table 2. Soil units and their characteristics after condensation

\begin{tabular}{ccccc}
\hline Period 1 & Period 2 & Num. of Period 1 & Num. of Period 2 & Legend \\
\hline Recent & Recent & 00 & 00 & 0000 \\
Quaternary & Holocene & 01 & 01 & 0101 \\
Quaternary & & 01 & 02 & 0102 \\
Quaternary & Pleistcene & 02 & 02 & 0202 \\
Neogene & Pliocene & 02 & 03 & 0203 \\
Neogene & & 03 & 03 & 0303 \\
Neogene & Miocene & 03 & 04 & 0304 \\
& & 04 & 04 & 0404 \\
Paleogene & Oligocene & 04 & 05 & 0405 \\
Paleogene & & 05 & 05 & 0505 \\
Paleogene & Eocene & 05 & 06 & 0506 \\
Paleogene & & 06 & 06 & 0606 \\
Paleogene & Palaeocene & 06 & 07 & 0607 \\
& & 07 & 07 & 0707 \\
Cretaceous & Upper Cretaceous & 08 & 08 & 0708 \\
& & 08 & 08 & 0808 \\
Period1 & Period 2 & Num. of Period 1 & Num. of Period 2 & Legend \\
Recent & Recent & 00 & 00 & 0000 \\
\hline
\end{tabular}

Table 3. Caption of a typical table.

\begin{tabular}{|c|c|c|}
\hline Soil Unit & Material & Consolidation \\
\hline Reclaimed fill & Sand and mud & Unconsolidated \\
\hline Filled up soil & Various & Unconsolidated \\
\hline Talus deposit & Gravel, sand and mud & Unconsolidated \\
\hline River bed sediment & Gravel, sand and mud & Unconsolidated \\
\hline Abandoned channel sediment & Muddy material & Unconsolidated \\
\hline Marine sediment & Muddy material & Unconsolidated \\
\hline Marine sediment & Sandy material & Unconsolidated \\
\hline Marine sediment & Gravelly material & Unconsolidated \\
\hline Fluvial sediment & Muddy material & Unconsolidated \\
\hline Fluvial sediment & Sandy material & Unconsolidated \\
\hline Fluvial sediment & Gravelly material & Unconsolidated \\
\hline Lacustrine sediment & Muddy material & Unconsolidated \\
\hline Lacustrine sediment & Sandy material & Unconsolidated \\
\hline Lacustrine sediment & Gravelly material & Unconsolidated \\
\hline Gotenba deiryu & Lapili and volcanic sand & Unconsolidated \\
\hline Kamiyama land slide sediment & Pyroclastic material & Unconsolidated \\
\hline Tachikawa loam & Volcanic ash & Unconsolidated \\
\hline Musashino loam & Pyroclastic flow & Unconsolidated \\
\hline Musashino loam & Volcanic ash & Unconsolidated \\
\hline
\end{tabular}




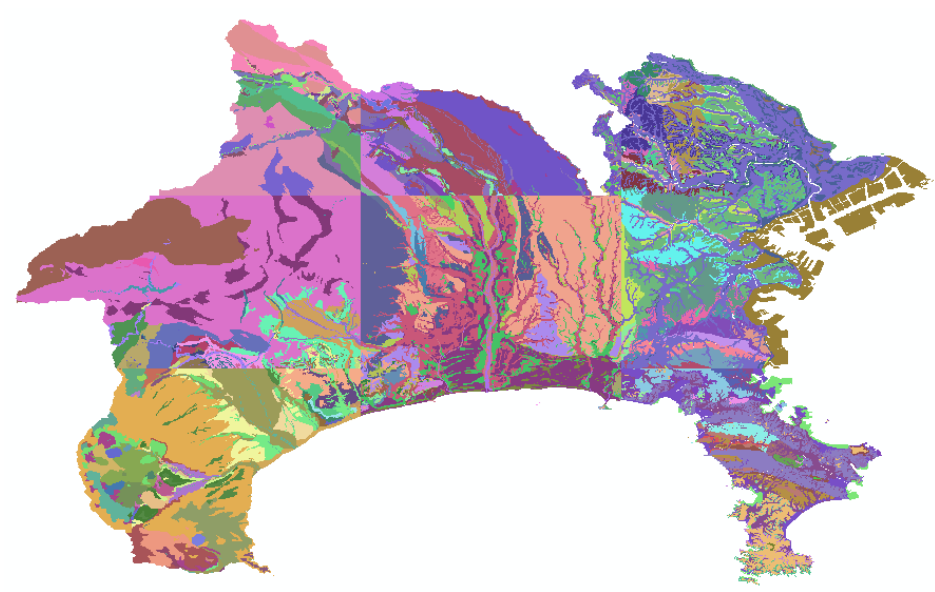

Figure 9. Result of digital geological map.

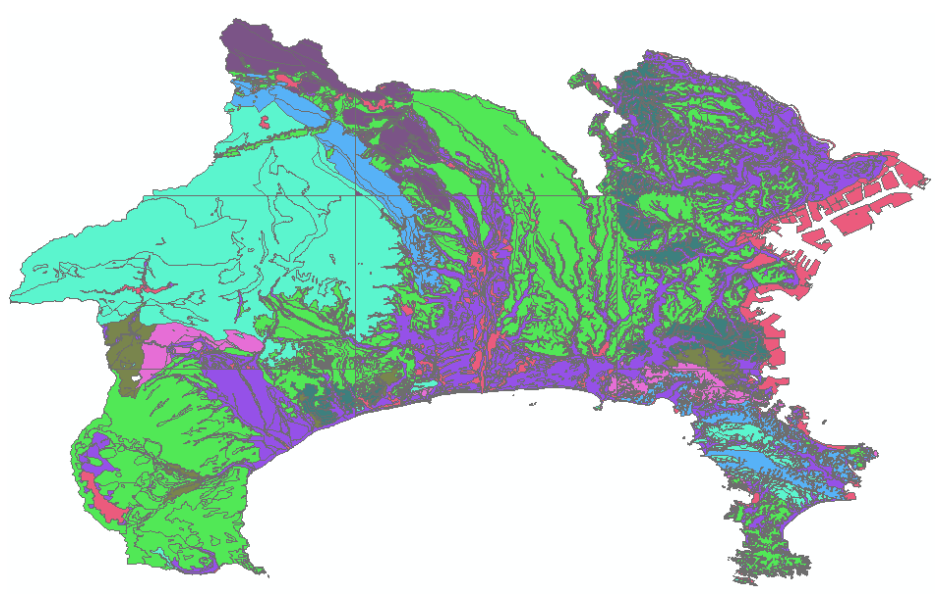

Figure 10. Classification of geological map based on geological periods.

\section{4. $50 \mathrm{~m}$ Mesh of the Digital Map}

In Japan, norm area mesh of $1 \mathrm{~km}^{2}$ has been developed for the national numerical land information. Related to the landform, the minimum $50 \mathrm{~m}^{2}$-mesh size of elevation data is also prepared. In this study, for the developing detail disaster map, also $50 \mathrm{~m}^{2}$ meshed according to the elevation data is adopted. Based on the longitude and latitude of the proper $1 \mathrm{~km}$ square used for the national numerical land information which has a grid size of 45 second (in the east and west direction) $\times 30$ second (in the south and north direction), a $20 \times 20$ divisions having a grid size of 2.25 second (in the east and west direction) $\times 1.5$ second (in the south and north direction) is built. The new mesh size is about $50 \mathrm{~m}^{2}$. Figure 11 shows the mesh process of the digital map. The purpose of the mesh is to get the attributions of digital map at the position of each grid of the $50 \mathrm{~m}^{2}$ mesh data. First, a polygon data of the $50 \mathrm{~m}^{2}$-mesh size is input into the ArcGIS, and the coordination system is defined to be same as the digital map. It is easy to find the center point of each grid of the polygon shape file, and a new point shape file is formed. Then the table joint function of ArcGIS can realize mesh efficiently. Cooperate the attributions of $50 \mathrm{~m}^{2}$ meshed point shape file and those of the 


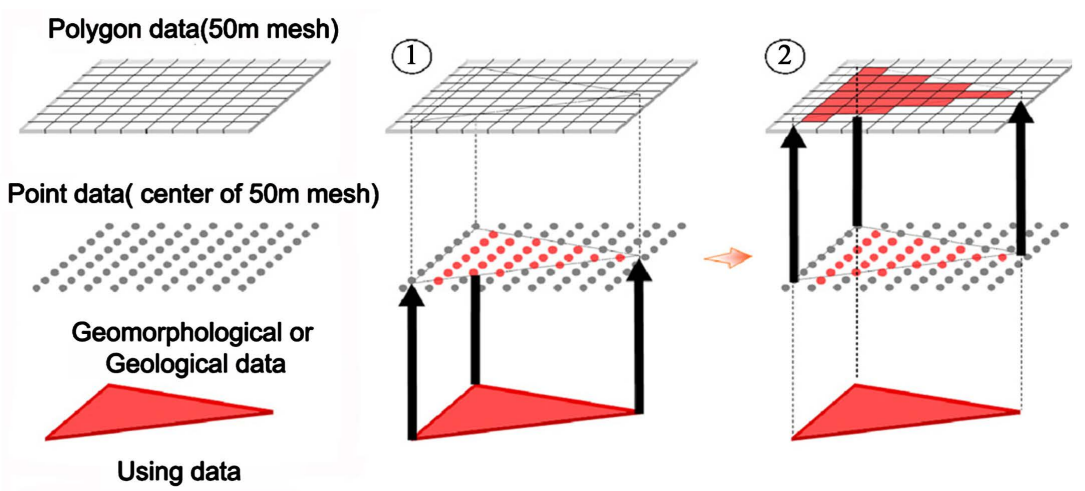

Figure 11. Manufacture process of $50 \mathrm{~m}$ meshed digital map.

polygon shape file of digital map based on the space position, and then the point shape file obtains its attributions. Using the table joint function again between the $50 \mathrm{~m}^{2}$ meshed polygon shape file and point shape file, the last $50 \mathrm{~m}^{2}$ meshed digital maps is achieved. Figure 12 and Figure 13 give the digital map with 50 $\mathrm{m}^{2}$ mesh. It can be shown that it has decomposition accuracy.

\section{Micro-Landform Classification}

According to the soil ground classification for predicting the strong ground motion, cases such as the categories of ground and geological classification etc. have been used. However, analysis results based on most of the ground strong motions show that in these ground categories the effective classification method to evaluate the ground effect is to use the topography categories. Making reference of the method of Midorikawa (Midorikawa, et al.) [16], according to the processing proposal of micro-landform classification from Central Disaster Management Council, 14 categories of micro-landform classification, i.e. Paleozoic and Mesozoic and Pre-Tertiary, Neocene, Hill, Volcanic and other Geom., Gravel Plateau, Loam Plateau, Valley Plain, Fan, Natural Levee, Delta and Back March (D $\leq 0.5 \mathrm{~km})$, Delta and BackMarsh (D > $0.5 \mathrm{~m})$, Sand Bar and Dune, Reclaimed Land and Artificial Transformed Land, are formed based on the $50 \mathrm{~m}$ meshed geomorphological and geological data. The results are shown in Figure 14.

\section{Amplification Ratios of Surface Ground}

However, the sit classifications are rather qualitative and subjective descriptions of side effects. For more quantitative evaluation of the site effects, a physical parameter should be used as parameter. The amplification factor has shown strong correlation with the share wave velocity of ground. In addition, by using strong motion records analysis results showed that the average share wave velocity could be common site parameter for evaluating the site effect in various regions (Midorikawa, et al.) [16].

Using the experience formulation form by Midorikawa (Midorikawa, et al.) [16], the relationship between micro-landform and AVS30 is defined as 


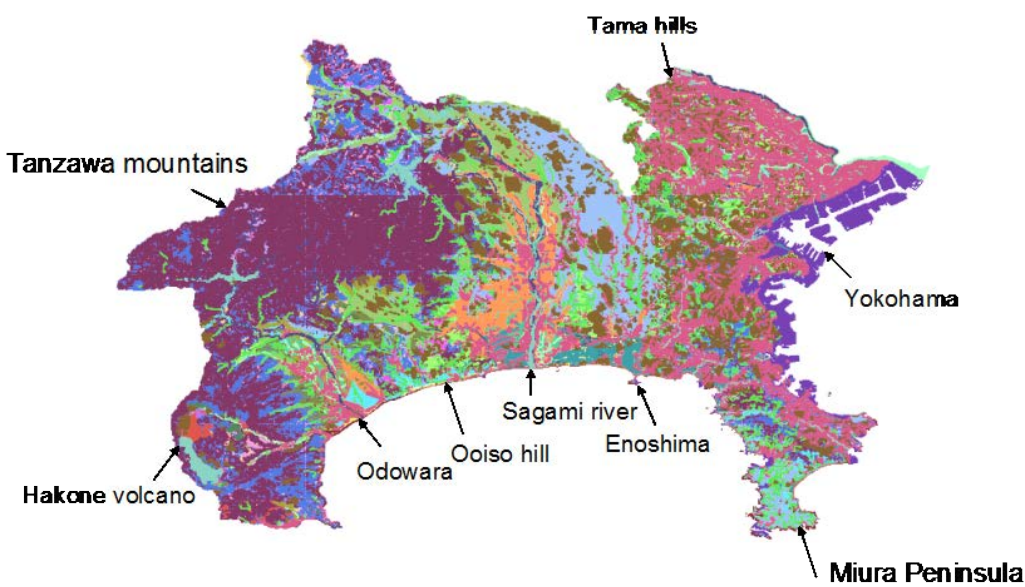

Figure 12. Conditions exhibited by $50 \mathrm{~m}$ meshed geomorphological map.

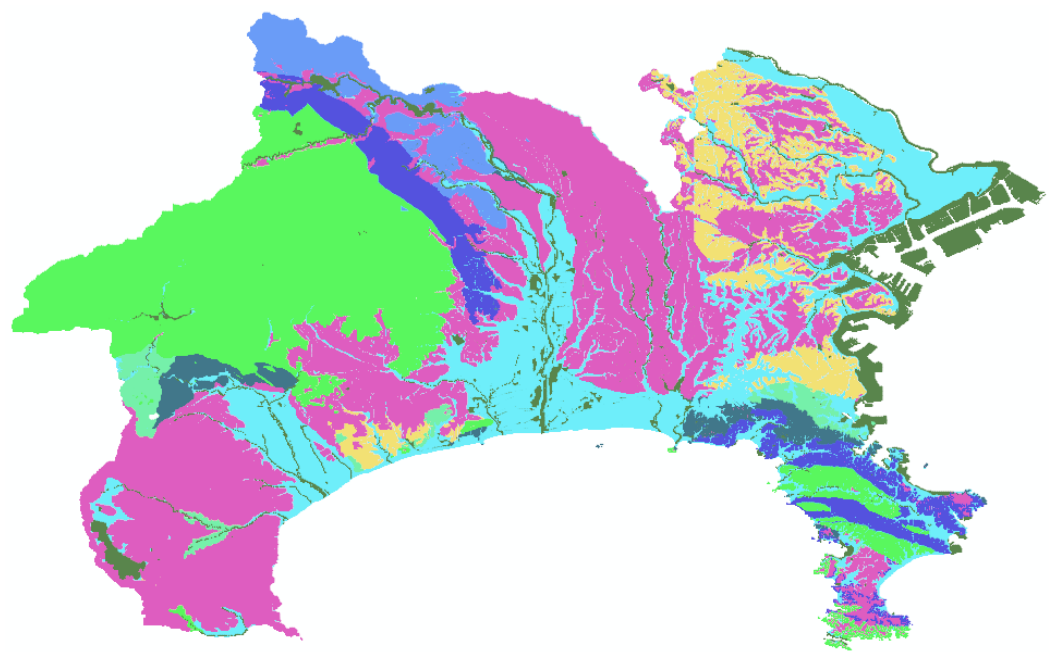

Figure 13. $50 \mathrm{~m}$ meshed geological map with legend unification.

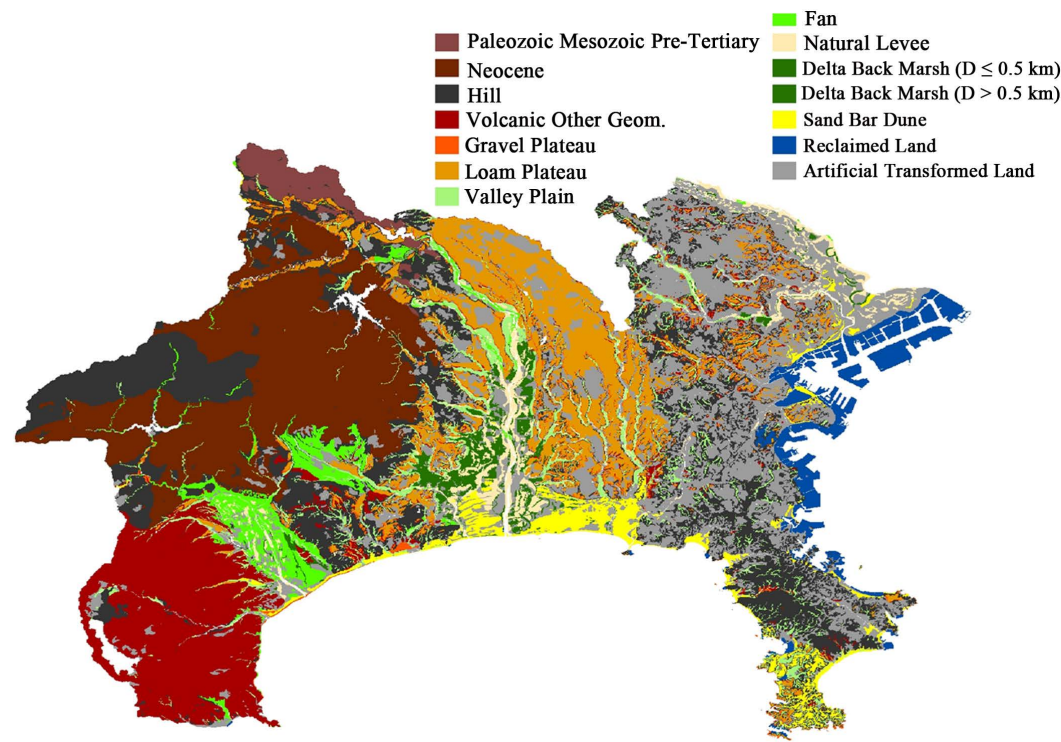

Figure 14. $50 \mathrm{~m}$ meshed micro-landform map. 


$$
\log \operatorname{AVS} 30=a+b \times \log H+c \times \log D \pm \sigma
$$

where, average share wave velocity of surface ground under $30 \mathrm{~m}$, is the elevation $(\mathrm{m})$, is the distance from main river $(\mathrm{km})$, the coefficients (related to the micro landform classification) and the standard deviation (related to the micro-landform classification)

To calculate the coefficients there are two cases depending on that the site coefficients corresponding to the micro-landform are possible or impossible to be obtained. In the first case, the values of AVS30 calculated based on the borehole data that has soil information underground with a deep of $30 \mathrm{~m}$ should be collected, and the borehole data is origin from the area of micro landform. Then the regression formulation is used and the site coefficients can be defined. In another case, the site coefficients are hard to be defined, and the coefficients according to the experience formulation are used. In this study, because the Kanagawa prefecture is a large area the collection of borehole data is a time consuming job, and until now, it is hard to get enough data. The coefficients formed by Fujimoto (Fujimoto, et al.,) are used in this paper. Basing the share wave velocity of soil ground collected in the whole nation area of Japan, the relationship between the average velocity of share wave and Fujimoto, and the scheme to calculate the average velocity of share wave considering the site characteristic is developed build the numerical soil classification information of whole land. Table 4 gives the results of coefficients regressed by Fujimoto, which are adopted in the paper.

In addition, the experience formulation used AVS30 and maximum velocity is adopted to define the amplification amplitude of surface ground. The formulation by Midorikawa (Midorikawa, et al., 1994) [16] obtained based on the strong ground motion records during the 1987 Chiba-ken-toho-oki, is given as

$$
\log G=1.83-0.66 \log \mathrm{AVS} 30 \pm 0.16
$$

where $G$ is the amplification amplitude of maximum velocity in surface ground corresponding to the maximum velocity in base ground that has $600 \mathrm{~m} / \mathrm{s}$ of share velocity.

By the Equation (2), the amplification ratios are calculated, the results is shown in Figure 15, by which the amplification degree of soil ground when seismic happens can be exhibited clearly.

\section{Earthquake Intensity}

If given seismic origin, the attenuation formulation of the ground depending on the distance from the seismic origin can be obtained (Fujimoto, et al., 2003) [17]. Then the maximum velocity of the surface ground can be calculated by multiplying the amplification ratio. This parts of study job are now being carried out.

\section{Conclusions}

In this paper, detailed digital topographical classification of Kanagawa Prefecture and soil dynamic characteristic map is manufactured. The method of $50 \mathrm{~m}$ 
Table 4. Landform classification and regression coefficients according to site area.

\begin{tabular}{|c|c|c|c|c|c|c|}
\hline \multirow{2}{*}{ Landform classification } & \multirow{2}{*}{ Site area } & \multicolumn{3}{|c|}{ Coefficients } & \multirow{2}{*}{ Value } & \\
\hline & & a & $\mathrm{b}$ & c & & \\
\hline \multirow{3}{*}{$\begin{array}{l}\text { Paleozoic, mesozoic, } \\
\text { pre-tertiary }\end{array}$} & $\mathrm{E}$ & & & & 33 & \\
\hline & $\mathrm{C}$ & 2.74 & 0 & 0 & 17 & 0.18 \\
\hline & $\mathrm{W}$ & & & & 131 & \\
\hline \multirow{3}{*}{ Neocene } & $\mathrm{E}$ & & & & 53 & \\
\hline & $\mathrm{C}$ & 2.66 & 0 & 0 & 20 & 0.15 \\
\hline & $\mathrm{W}$ & & & & 39 & \\
\hline \multirow{3}{*}{ Volcanic, other geom. } & $\mathrm{E}$ & & & & 27 & \\
\hline & $\mathrm{C}$ & 2.36 & 0.11 & 0 & 30 & 0.16 \\
\hline & $\mathrm{W}$ & & & & 47 & \\
\hline \multirow{3}{*}{ Hill } & $\mathrm{E}$ & 2.60 & & & 22 & 0.19 \\
\hline & $\mathrm{C}$ & 2.48 & 0 & 0 & 36 & 0.12 \\
\hline & $\mathrm{W}$ & 2.60 & & & 11 & 0.21 \\
\hline \multirow{3}{*}{ Gravel Plateau } & $\mathrm{E}$ & 2.57 & 0 & 0 & 55 & 0.14 \\
\hline & $\mathrm{C}$ & & & & 49 & \\
\hline & $\mathrm{W}$ & 2.32 & 0.12 & 0 & 53 & 0.13 \\
\hline \multirow{3}{*}{ Loam platau } & $\mathrm{E}$ & 2.47 & 0 & 0 & 34 & 0.12 \\
\hline & $\mathrm{C}$ & 2.10 & 0.21 & O & 129 & 0.13 \\
\hline & $\mathrm{W}$ & $(2.10)$ & $(0.21)$ & 0 & 1 & - \\
\hline \multirow{3}{*}{ Fan } & $\mathrm{E}$ & 0.17 & 0.17 & & 58 & 0.15 \\
\hline & $\mathrm{C}$ & 2.04 & 0.23 & 0 & 40 & 0.12 \\
\hline & $\mathrm{W}$ & 2.31 & 0.14 & & 69 & 0.11 \\
\hline \multirow{3}{*}{$\begin{array}{l}\text { Sand bar, } \\
\text { dune }\end{array}$} & $\mathrm{E}$ & & & & 6 & \\
\hline & $\mathrm{C}$ & 2.34 & 0 & 0 & 16 & 0.15 \\
\hline & W & $(2.34)$ & (0) & $(0)$ & 3 & - \\
\hline \multirow{3}{*}{ Valley Plain } & $\mathrm{E}$ & 2.50 & 0 & & 20 & 0.13 \\
\hline & $\mathrm{C}$ & 2.06 & 0.22 & 0 & 71 & 0.13 \\
\hline & W & 2.25 & 0.18 & & 23 & 0.12 \\
\hline \multirow{3}{*}{ Natural levee } & $\mathrm{E}$ & 2.37 & 0 & & 10 & 0.14 \\
\hline & C & 2.13 & 0.17 & 0 & 42 & 0.16 \\
\hline & $\mathrm{W}$ & 2.29 & 0.13 & & 24 & 0.07 \\
\hline \multirow{2}{*}{$\begin{array}{c}\text { Delta } \\
\text { back march }\end{array}$} & $\mathrm{E}$ & 2.31 & \multirow{2}{*}{0} & \multirow{2}{*}{0} & 24 & 0.18 \\
\hline & $\mathrm{W}$ & 2.35 & & & 67 & 0.13 \\
\hline $\mathrm{D} \leq 0.5 \mathrm{~km}$ & C & 2.28 & 0 & 0.3 & 103 & 0.14 \\
\hline $\mathrm{D}>0.5 \mathrm{Km}$ & $\mathrm{C}$ & 2.19 & 0 & 0 & 73 & 0.15 \\
\hline \multirow{3}{*}{$\begin{array}{c}\text { Artificial } \\
\text { transformed land }\end{array}$} & $\mathrm{E}$ & $(2.10)$ & $(0.20)$ & $(0)$ & 4 & - \\
\hline & $\mathrm{C}$ & 2.10 & 0.20 & 0 & 43 & 0.11 \\
\hline & $\mathrm{W}$ & 2.50 & 0 & 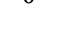 & 14 & 0.23 \\
\hline \multirow{3}{*}{$\begin{array}{l}\text { Reclaimed } \\
\text { land }\end{array}$} & $\mathrm{E}$ & $(2.21)$ & $(0.08)$ & $(0)$ & 0 & - \\
\hline & C & 2.21 & \multirow{2}{*}{0.08} & \multirow{2}{*}{0} & 207 & \multirow{2}{*}{0.14} \\
\hline & W & 2.31 & & & 81 & \\
\hline
\end{tabular}




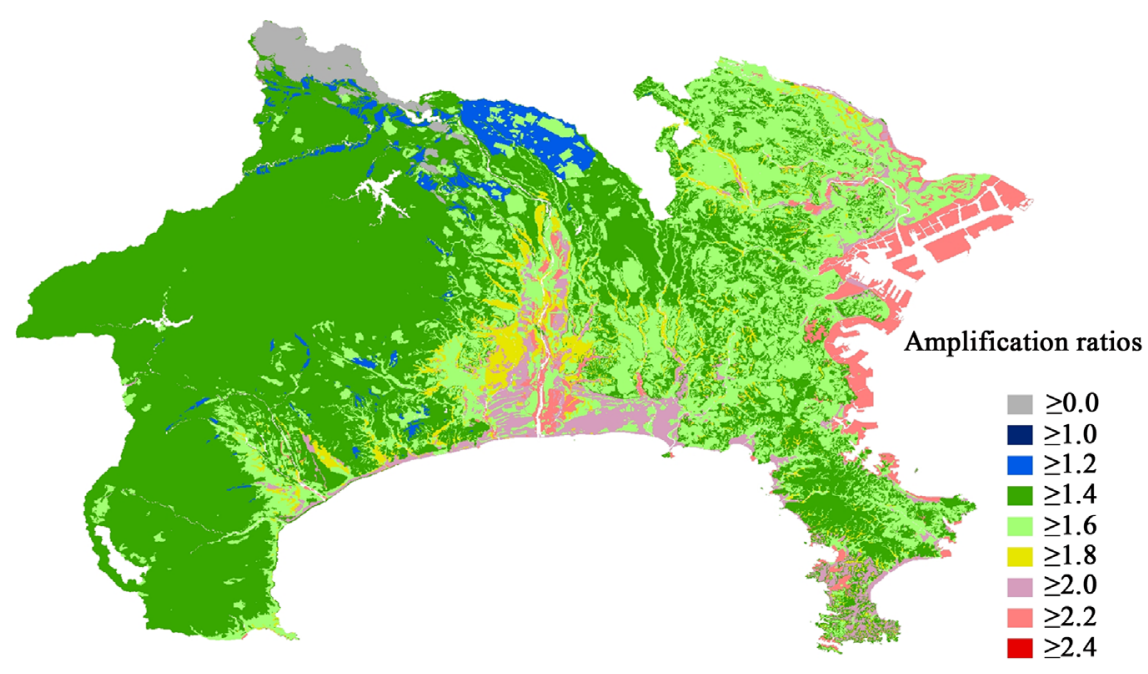

Figure 15. $50 \mathrm{~m}$ meshed amplification ratio map.

meshed geomorphological or geological using geographic information systems (GIS) is introduced. 15 categories of micro-landform classification are formed based on the digital soil classification data, and the amplification ratios of surface ground are estimated. The conclusions are summarized as:

1) The digital map with $50 \mathrm{~m}$ mesh size is enough for considering potential risk damage analysis on a city, a county or award as detailed information.

2) As digitalization and mesh approach of the geomorphological and geological map, GIS has provided an efficient tool for precise damage evaluation.

3) The developed amplification map has exhibited direct information of the dynamic characteristic distribution of Kanagawa Prefecture. Earthquake intensity map of the whole prefecture is now being developed.

\section{Acknowledgements}

This research received support from Mahmood Rahimianby Kanagawa University. I thank you for writing here.

\section{Conflicts of Interest}

The authors declare no conflicts of interest regarding the publication of this paper.

\section{References}

[1] Eurocode No. 8 (1998) Design of Structures for Earthquake Resistancd. Commission of the European Communities, Doc CEN/TC250/SC8/N335.

[2] NEHRP (2003) Recommendation Prevision for Seismic Regulation for New Buildings and the Structures. Building Seismic Safety Council, Washington.

[3] Fujiwara, H., et al. (2011) Development of Geological Information Database for Modeling of Underground Structure of Whole of Japan for Earthquake Disaster Prevention. Proceedings of 5 th Symposium on Development of Integrated Geophysical and Geological Information Databese, Tokyo, March 2011. 
[4] Midorikawa, S., et al. (2011) Application of High Resolution Seismic Hazard Map to Seismic Risk Evalution. Proceedings of 5 th Symposium on Development of Integrated Geophysical and Geological Information Databese, Tokyo, March 2011.

[5] NIED (2011) Report on Development of an Integrated Geophysical and Geological Information Database. Technial Note of the National Research Institute for Earth Science and Disaster Prevention, No. 361.

[6] Navarro, M., et al. (2014) Earthquake Ground Motion Characteristics of Lorca Town (SE Spain). Proceedings of the International Symposium on Geohazards. Science, Engineering and Management, Paper No. EQ-14.

[7] Benito, M.B., et al. (2010) A New Seismic Hazard Assessment in the Region of Andalusia (Southern Spain). Bulletin of Earthquake Engineering, 8, 739-766.

https://doi.org/10.1007/s10518-010-9175-9

[8] Gaspar-Escribano, J., et al. (2010) From Regional to Local Scale Seismic Hazard Assessment: Example from Southern Spain. Bulletin of Earthquake Engineering, 8, 1547-1567. https://doi.org/10.1007/s10518-010-9191-9

[9] Rota, M., et al. (2011) Typological Seismic List Maps for Italy. Earthquake Spectra, 27, 907-926. https://doi.org/10.1193/1.3609850

[10] Navarro, M., et al. (2014) Local Site Effect Microzonation of Lorca Town (Southern Spain). Bulletin of Earthquake Engineering, 12, 1933-1959.

https://doi.org/10.1007/s10518-013-9491-y

[11] Pertersen, M.D., et al. (2015) The 2014 United States National Seismic Hazard Model. Earthquake Spectra, 31, S1-S30.

[12] The Cabinet Office (2005) Technical Report on Creation of Seismic Disaster Prevention Map. Disaster Prevention Section of Cabinet Office.

[13] Ochiai, T., et al. (2010) Research on Creation of Digital Detailed Area Risk Map and Its Support System to Regionally Self-Disaster Prevention Activity. Japan Earthqu. Eng. Sympo, 13, 2035-2038.

[14] Japan Meteorological Agency (2018) How Earthquakes Occur. https://www.jma.go.jp

[15] Moroi, T., et al. (2002) Re-Evaluation on the Damage Statistics of Wooden Houses for the 1923 Kanto Earthquake and Its Seismic Intensity Distribution in and around Southern Kanto District. Japan Association for Earthquake Engineering, 2, 35-71.

[16] Midorikawa, S., et al. (1994) Effect of Strong Motion Records Observed during the 1987-Chiba-ken-toho-oki. Japan Earthquake. Eng. Sympo, 3, 85-90.

[17] Fujimoto, K., et al. (2003) Average Shear-Wave Velocity Mapping throughout Japan Using the Digital National Land Information. Japan Association for Earthquake Engineering, 3, 13-27. 